\title{
The Importance of Citizen Scientists in the Move Towards Sustainable Diets and a Sustainable Food System
}

\section{OPEN ACCESS \\ Edited by:}

Tamara Alhambra-Borrás,

University of Valencia, Spain

Reviewed by:

Jill K. Clark,

The Ohio State University,

United States

Stellah Mikalitsa Mukhovi,

University of Nairobi, Kenya

*Correspondence:

Christian Reynolds

christian.reynolds@city.ac.uk

Specialty section:

This article was submitted to

Social Movements, Institutions and

Governance,

a section of the journal

Frontiers in Sustainable Food Systems

Received: 19 August 2020

Accepted: 30 June 2021

Published: 20 September 2021

Citation:

Oakden L, Bridge G, Armstrong B,

Reynolds $C$, Wang $C$, Panzone $L$,

Rivera XS, Kause A, Ffoulkes C,

Krawczyk C, Miller G and Serjeant S

(2021) The Importance of Citizen

Scientists in the Move Towards

Sustainable Diets and a Sustainable

Food System.

Front. Sustain. Food Syst. 5:596594.

doi: 10.3389/fsufs.2021.596594

\author{
Libby Oakden ${ }^{1}$, Gemma Bridge ${ }^{2}$, Beth Armstrong ${ }^{3}$, Christian Reynolds s,4*, \\ Changqiong Wang ${ }^{5}$, Luca Panzone ${ }^{6}$, Ximena Schmidt Rivera $^{7}$, Astrid Kause ${ }^{8}$, \\ Charles Ffoulkes ${ }^{9}$, Coleman Krawczyk ${ }^{10}$, Grant Miller ${ }^{11}$ and Stephen Serjeant ${ }^{12,13}$ \\ ${ }^{1}$ Independent Researcher, London, United Kingdom, ${ }^{2}$ Leeds Business School, Leeds Beckett University, Leeds, \\ United Kingdom, ${ }^{3}$ Department of Geography, Faculty of Social Sciences, The University of Sheffield, Sheffield, \\ United Kingdom, ${ }^{4}$ Center for Food Policy, University of London, London, United Kingdom, ${ }^{5}$ Wolfson Institute of Preventive \\ Medicine, Barts and The London School of Medicine \& Dentistry, Queen Mary University of London, London, \\ United Kingdom, ${ }^{6}$ Applied Economics and Social Science, School of Natural and Environmental Sciences, Agriculture \\ Building, King's Road, Newcastle University, Newcastle upon Tyne, United Kingdom, ${ }^{7}$ Equitable Development and Resilience \\ Research Group, Department of Chemical Engineering, Institute of Energy Futures, College of Engineering, Design and \\ Physical Sciences, Brunel University London, Uxbridge, United Kingdom, ${ }^{8}$ Centre for Decision Research \& Priestley \\ International Centre for Climate, University of Leeds, Leeds, United Kingdom, ${ }^{9}$ RSK ADAS Ltd, Abingdon, United Kingdom, \\ ${ }^{10}$ Institute of Cosmology \& Gravitation, University of Portsmouth, Portsmouth, United Kingdom, ${ }^{11}$ Zooniverse, Oxford, \\ United Kingdom, ${ }^{12}$ School of Physical Sciences, The Open University, Milton Keynes, United Kingdom, ${ }^{13}$ Department of \\ Physics, Oxford University, Oxford, United Kingdom
}

To enhance sustainability, the food system requires significant shifts in the production, processing and supply of food. Ideally, a sustainable food system should operate, not only to protect the biosphere, but also to provide nutritious, high-quality food, and to support social values, an equitable economy, and human and animal health. It should also be governed responsibly within a supportive policy environment. Implementing these shifts is a task of immense scale; but citizen participation/engagement has the potential to help make sustainability a reality through distributed learning, dynamic sensing, and knowledge generation. Technological advancements in sensing and data processing have enabled new forms of citizen participation in research. When food system research is embedded within society it can help us to understand which changes towards sustainability work and which do not. Indeed, citizen engagement in food systems research has the potential to help bring citizens on side, supporting the growth of a food culture of resilience and of sustainable practises (including dietary change). This commentary provides examples of how existing research and alternative food production systems and agroecological practises may provide possible frameworks for citizen participation in food system studies. We highlight potential future food and citizen science approaches. Widening citizen participation and encouraging the involvement of other food system actors, including those in local, national and international governance, is essential to capture the full potential of citizen science in enabling transition to a sustainable food system. For the research community citizen science offers engagement and empowerment of wider communities with science; collecting and analysing data; and creating viable solutions to food system and diet issues.

Keywords: citizen science, participatory research, food systems, sustainable diets, co-development, widening participation 


\section{PERSPECTIVE}

The food system today is estimated to contribute up to $37 \%$ of global greenhouse gas emissions (Poore and Nemecek, 2018; Mbow et al., 2019). Current methods of food production are contributing to significant environmental stress and damage to ecosystems, climate and biodiversity (Tilman and Clark, 2014; Poore and Nemecek, 2018). Such production driven damage is one of the significant negative pressures on food security (Vermeulen et al., 2012).

With increasing global urbanisation (68\% of people will live in cities by 2050), and a greater reliance on heavily processed, environmentally costly and health damaging diets (Popkin, 2017), the impact of the food system on climate is set to increase by $50-90 \%$ over coming years (Springmann et al., 2018). As such, there is a need for drastic change to transform the food system and minimise its impact on climate and dietary health.

However, achieving sustainability in a highly complex technological production driven food system is challenging. The traditional "farm to fork" system is inadequate and implies linearity, whereas food is present within a global network linked to other resources such as energy and water (Hoolohan et al., 2019). The network is largely invisible to city dwellers, but it supports, shapes and is shaped by urban living (Steel, 2008).

Further complicating matters is the notion that the food system contains numerous feedback loops which refer to the process by which change in one area of the system can affect change in distant parts of the system (Ingram, 2011). For instance, changes in soil fertility or biodiversity may result in lower crop yields which could have a knockknock-on effect on consumers by reducing the availability of food. Another example could be the liberalisation of food related trade policies such as those related to sugar, which could in turn negatively affect human health (Thow and Hawkes, 2009). Scientific enquiry, by its nature, forms hypotheses and tests narrowly. Understanding why and how to alter complex systems, requires an environment that is responsive to dynamic change. Single feedback loop learning is insufficient, "double loop" or "regenerative learning" is essential, for understanding and intervening in such dynamic systems (Food and Agriculture Organization of the United Nations, 2018; Schröder et al., 2019). As such, attaining a truly equitable sustainable food system, for and in cities, presents a significant challenge (Lang and Mason, 2017a,b; Sonnino et al., 2019).

Despite the challenges, food system change is needed as it could help slow the rate of warming through reduced greenhouse gas emissions (Committee on Climate Change, 2020; Reynolds, 2020) and could deliver co-benefits by helping to reduce dietrelated chronic diseases such as diabetes and obesity (Steenhuis and Vermeer, 2009; Anand et al., 2015). The feasibility of such changes was described in the "EAT-Lancet" report on sustainable diets which established nutritionally adequate and culturally acceptable food supply for all people is possible within planetary boundaries (Willett et al., 2019). However, the report was criticised for failing to describe how such dietary changes could be achieved in all cities, countries and cultures (Torjesen, 2019).
Transition to a food system which is sustainable, healthy, equitable, resilient, potentially regenerative, and suitable for communities globally, will require multi-level knowledge, new technologies, new and/or different behaviours and policies. It is also important to consider that food practices and dietary habits are embedded in culture and informed by tradition (Warde, 2016). The cultural and temporal routines of everyday life, shape eating practices and the ability to change these routines as individuals desire (Hoolohan et al., 2018; Mylan, 2018). Food practices are socio-cultural, and they are situated in the food system that shapes the food environment (Kopelman et al., 2007). This embeddedness can be an asset for food system science. By studying practices collaboratively, barriers and solutions may be identified, awareness raised and generate new ideas for shifting food practices, diets, and the wider related food system(s) (Hoolohan et al., 2018).

Citizen science is a participatory research method that actively involves citizens in scientific enquiry to generate new knowledge or understanding. There is no one definition of the method but citizen science projects involve engaging with communities and seeking their participation in data classification, collection, and/or co-creation (Reynolds et al., 2021). If citizen science engages a diversity of publics (Sauermann et al., 2020), enabled by scientists who are citizen advocates (Stilgoe, 2009) it can be a powerful collaborative approach that can generate and/or, analyse data, help monitor progress, and bring fresh perspectives. These outcomes could stimulate a faster and smoother transition to sustainable diets and a wider sustainable food system.

\section{Citizen Science in the Food System}

Although citizen scientists have been employed in environmental and ecological systems research since the 19th and early 20th century (Haklay, 2013), enabling researchers to gather more data, with a wider geographic spread and over longer periods than possible otherwise (Haklay, 2013; Strasser et al., 2018). Engaging citizen scientists in food system research only started to gain momentum in 2019. For instance, engaging with members of the public to assess food fraud or stimulate local food production, and involving citizen scientists in food safety research or monitoring (see Reynolds et al., 2021). Such studies are becoming a possibility as a result of advances in remote forensic and sensing technologies (Dehnen-Schmutz et al., 2016; Yano et al., 2018).

\section{Method}

A rapid literature review (on Scopus, and Google Scholar) was conducted in March to June 2020 (see Tricco et al., 2015 and Haby et al., 2016 for discussion of the characteristics, strengths and limitations of this methodology). The review was used to explore the terms that describe participatory methods: citizen science, participatory research, community research, action research and coproduction. These results were interrogated for "food system" and related terms including: food, diet, obesity, nutrition, agriculture, farming, urban growing/farming, fish, food and safety, and variants of these terms. From this initial search further papers were reviewed if cited within relevant papers or if they referenced them (using snowball method). The examples identified and discussed through this review are 


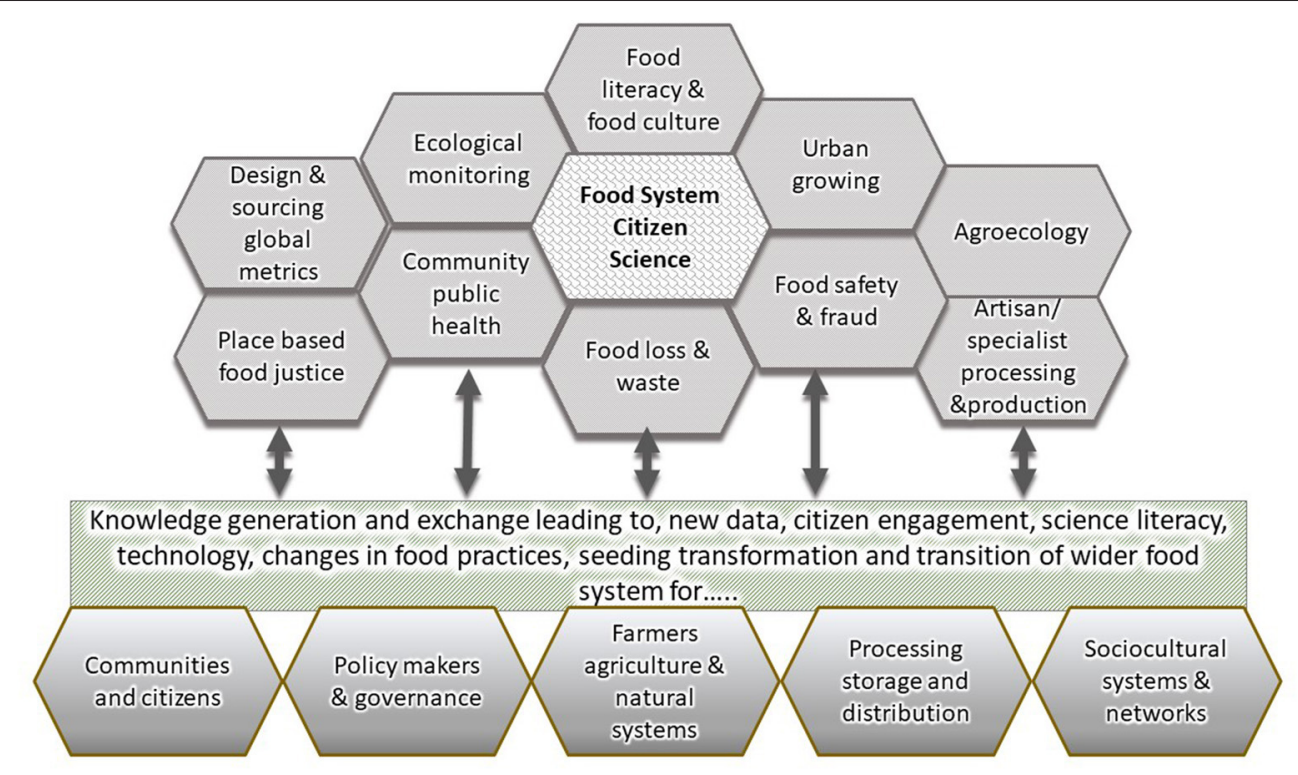

FIGURE 1 | A pictorial summary of citizen science engagement with the food system and impact pathways. These examples were identified through our rapid review of the literature in 2020. Examples of domains where citizen or participatory science is linked to food system research and experimentation (upper hexagons). Knowledge is generated by citizen scientists supported and/or catalogued by professional researchers to inform or modify practices within the food system dynamically (oblong). Transformation is possible in different spheres linked to food and for different food system actors (lower hexagons).

categorised and shown in Figure 1. While by no means an exhaustive list, these examples do highlight the state of the literature in early 2020.

Further searching using Google Scholar was carried out in December 2020 using additional food system search terms such as antimicrobial resistance, AMR, food safety, food pathogens, food additives, etc. (see Reynolds et al., 2021, for the full results of this additional study).

The aim of this perspective is to provide examples from the literature to illustrate citizen involvement in diverse domains of food systems and sustainable diet research. A summary of the examples discussed is provided in Figure 1. Eight of the ten food citizen science domains illustrated in the figure are discussed in this paper. Citizen science for tackling food waste (Pateman et al., 2020 this issue), food safety (Reynolds et al., 2021), sourcing global sustainability metrics [for Sustainable Development Goal [SDG]], collection of data and design of evaluation metrics monitoring food and agriculture related SDGs (Ryan et al., 2018; Fritz et al., 2019) are reviewed elsewhere. We also recognise the additional research from this special issue including Kallio and Houtbeckers (2020), Sijtsema et al. (2020), and Helenius et al. (2020). We highlight that our examples are focused on citizen science at the production, processing and consumption stages of the food system, with food system inputs (natural resources, manufactured inputs or human resources) all offering their own potential citizen science engagement opportunities. Indeed, examples of irrigation (Buytaert et al., 2014; RamirezAndreotta et al., 2015; Pérez-Belmont et al., 2019), fossil fuel (Zilliox and Smith, 2018) or other input-based citizen science are currently present in the literature (Dobson et al., 2021).
We also note the American-Anglo-Euro-centric nature of our examples provided, with no studies from Latin America, Asia and Africa were highlighted by our rapid review (beyond Japan and Cuba). Through our informal networks we are aware of ongoing citizen science and food work globally, and hope this is published soon to provide stronger evidence of the wide applicability and adaptability of citizen science methods to global food system and diet issues.

\section{Example 1 Ecological Monitoring}

In ecological monitoring projects, citizen scientists typically use geographic information systems or environmental sensing to enhance the productivity of a research project, allowing large scope, geographically and/or temporally (Sauermann et al., 2020). Such studies may use geolocation distributed and miniaturised sensing with recruitment of often large numbers of collaborating citizen scientists.

An example of citizen scientists in food systems research is the engagement of school children to monitor soil health (Martay and Pearce-Higgins, 2018). Other examples include the engagement of volunteers from diverse community groups (together with organisations who contributed additional funding) to undertake a mussel pathogen survey (Puget Sound, Washington, USA) whereby volunteers collected samples and carried out analysis, allowing survey sites number to rise from 60 to 108 (Lanksbury et al., 2013). Another example includes the global Local Environmental Observer (LEO) project which is a community situated network (originating in Alaska) that has tested for food pathogens, and monitored for 
advanced permafrost melting, helping safeguard household and community food storage depots (Mosites et al., 2018).

Ecological and environmental monitoring of geographically distant sites and systems by citizen scientists can enable early detection of environmental change and identification of food system risks. Working together, professional and citizen scientists have realised ambitious scientific aims that would remain out of reach without such partnerships. These examples and those in the following sections demonstrate that when citizens actively participate in research, outcomes can be broader than traditional knowledge generation and exchange, scientific literacy gains and engagement.

\section{Example 2 Urban Growing}

Urban growing is increasingly seen as an important step for food security in modern societies. For instance, the German "1000 gardens" project aimed to reduce reliance on imported soya used citizen generated data to investigate suitability of growing conditions in different geographies for up to 10 lines of soya beans and subsequently evaluate usefulness of the beans for different purposes (Würschum et al., 2019). Media coverage of this project raised national awareness of the importance of legumes, both as food and for soil health.

The MY Harvest initiative located in the UK, investigated the geography of urban food growing, examining the scale of urban cultivation and yields in Leicester (Edmondson et al., 2020). Citizen scientists from growing spaces and allotments, collected yield data on what is grown where. These data, geographic information systems data and historical data were combined to estimate the size and efficiency of current urban cultivation and describe areas that could be used to maximise urban growing. Such projects have the potential to bring improvements in food security and food sovereignty to urban areas, whilst also increasing the engagement of citizens, local government and researchers in urban growing. Such collaborative projects highlight that with the right support, positive health community and environmental benefits can accrue (Beilin and Hunter, 2011; Dobson et al., 2020), as reported in the wider "urban food growing" literature (reviewed in Edmondson et al. (2020)).

These examples have focused on growing, rather than consumption of food. This area of research could be easily expanded to examine diets in relation to growing food; possibly even trace how the urban community networks use and consume the food beyond the individual level. This would provide another facet of investigation for sustainable urban growing citizen science projects.

\section{Example 3 Agroecology}

Whilst MY Harvest and 1,000 Gardens were relatively limited projects, there are larger scale and more longstanding examples of urban production implemented by citizen agroecologists. In 1990's, the collapse of the eastern bloc left Cuba without sufficient fertiliser supplies and other key farm inputs and forced an agricultural rethink. Numerous grass roots production projects in community growing spaces and free urban plantable spaces emerged (Altieri et al., 1999). Cuban urbanites experimented, generating and sharing knowledge, often in cooperative groups, to improve their food sovereignty and security (Buchmann, 2009).

More broadly across Cuba, agroecological farm scale production had to be adopted. Although mainstream experimentation and knowledge sharing was not directly carried out by traditional government extension services personnel, it was both developed and disseminated by Campesino "peasant" farmer community networks. Extension experts facilitated the peer to peer work, to ensure that farmer-led networks developed skills and shared knowledge through collaboration and participation (Rosset et al., 2011; Rosset and Val, 2019).

\section{Example 4 Artisanal or Specialist Food Processing and Production}

Artisanal food production is another form of (long term) community-based science. Through iterative processes of experimentation and evaluation, practices are gradually incorporated into everyday life, aided by peer networks and external experts (e.g., brewers or bakers) (Kuznetsov et al., 2016; Reese et al., 2020).

Users of the commercial food-substitute Soylent, engage in more individualistic food production. Rather than buying Soylent, some users modify the open-source recipe, optimising the nutritional profile for perceived improved health outcomes. Soylent practitioners supported and collaborated accross the user-community. Whilst the scientific literacy is admirable, the authors are justified in their criticisms of the research, highlighting the importance of developing proper data handling and support structures within this and any future citizen scientist-led communities (Dolejšová and Kera, 2017).

At the most radical end of the spectrum of citizen scientist producers are "biohackers" such as Real Vegan Cheese biohacking group, who are developing methods to produce milk proteins from baker's yeast in order to make vegan cheese (see Wilbanks, 2017) or the Shojin Meat project, which developed techniques to produce lab-grown meat [Disrupting Japan, 2021; Shojinmeat Project, 2021]. Groups include professional biologists and members with complementary skills, collaborating to develop foods such as vegan cheese or lab-grown meat. These are some of the most high-tech and specialised citizen food science projects documented, and reflect local available infrastructure and enabling entrepreneurial environments.

Artisanal producers, Soylent experts and Biohacking groups practice "extreme" citizen science (Haklay, 2013). These projects demonstrate citizen science can be sophisticated, selforganising and largely independent of traditional institutions and professionals. Accessibility of technology, experts or expert information, good governance and "peer to peer" support, are prerequisites of extreme citizen science.

\section{Example 5 Food Safety and Fraud}

Emerging technology may provide a means for more citizen participation in food safety science. Equipment required for complex testing (e.g., for molecular testing) has become more user friendly and cheaper. Citizen scientists have used genetic testing to detect food fraud (Bénard-Capelle et al., 2015; Warner et al., 2019). Emerging technology presents opportunities for 
democratised food safety testing (Nielen, 2019). Indeed, investors are backing allergen testing tech start-ups (Ross et al., 2018), and other food safety technology is close to market (QuesadaGonzález and Merkoçi, 2017; Naydenova et al., 2019).

Following the Fukushima nuclear disaster in Japan, a citizen scientist network began monitoring radiation levels in contaminated food in response to a lack of information and mistrust in the government/available information. "Citizen Radioactivity Monitoring Stations" were varied in nature, but commonalities between stations were that they were selforganising, efficient and practiced "open source" data sharing. The professionalism of the network (many degree level scientific training) was perceived as a threat by the radiological protection establishment (Reiher, 2016).

However, we highlight that citizen food safety projects could be viewed positively (and harnessed) by policy makers and professional scientists to reinforce food safety and trust. Indeed, public confidence and trust in food is needed to accelerate the transformations toward a healthy sustainable food system. Rapidly developing technology, citizen expertise and scientific literacy can allow higher levels of citizen participation. Policy makers and professional scientists could engage with citizen scientists and emerging technology to rapidly improve public health and trust in the food system.

\section{Example 6 Community-Based Public Health}

Public health and nutrition professionals use participatory, community-based methods to co-develop interventions e.g., health marketing studies in difficult to reach urban (George et al., 2016) and rural low socioeconomic status communities (Mammen et al., 2019). Co-creation of knowledge can empower citizens; generate agency, self-efficacy and promote citizen advocacy (for review see Israel et al., 1998).

A common participatory or collaborative research approach is Onevoice or Photovoice methodology (Sutton-Brown, 2014). Skills training and technological tools (e.g., cameras) are given to citizens, allowing them to take films, photographs or record sounds; collecting impressions about everyday experiences and environment. Professional researchers facilitate review and discussion, where participants are encouraged to analyse findings through development of ideas and insights. Other community actors may collaborate co-developing mitigating strategies and/or policies (for review see (Derr and Simons, 2020)).

Studies often examine enablers and barriers to health and food practice (Kovacic et al., 2014; Díez et al., 2018; Rogers et al., 2018). Communities and policy makers, (e.g. Madrid Spain) can develop place based mitigations for health, such as getting local stores to set up collective buying practices so that diabetic and gluten free foods were available widely and at reasonable cost (Díez et al., 2018). Citizen scientists in New Jersey (USA) identified problems with a Healthy corner stores' scheme and suggested strategies for stores' to collaboratively modify logistics, improving implementation (Chrisinger et al., 2018). Other community only solutions may be more limited e.g., sharing recipes and meeting to cook healthier foods together (Rogers et al., 2018).
Youth participation in a photovoice food justice project demonstrated that students became engaged and advocated for food equity in their community (Harper et al., 2017). Though unsuccessful, these events prompted discussion about the potential of using engagement and empowerment of youth groups more effectively in food justice research to balance power dynamics (Harper et al., 2017).

Another extensive youth public health photovoice project, revealed that although participants were engaged, empowered and proposed solutions. Yet, efforts to affect change were similarly hampered by structural and policy barriers (Kovacic et al., 2014).

Use of technology can improve participation but also increase levels of empowerment in participatory science projects (Akom et al., 2016). Diverse and extensive participation, must be enabled and include policy makers and those with responsibility for governance to enable more dynamic community led policy change.

\section{Example 7 Place-Based Citizen Science}

Engaging diverse stakeholders, to maximise citizen science efficiency and effectiveness, may be essential for many transition approaches towards a sustainable food system. The examples below highlight how place-based citizen science projects can improve a specific food-place, food geography or food environment. Project SoL (Sundhed og Lokalsamfund, or translated: Health and Local communities) in Bornholm, Denmark was a local community led public health intervention, to reduce childhood overweight and obesity (Bloch et al., 2014; Toft et al., 2018). Eighty-six percent of the local population were aware of SoL, families made healthier food purchases and there was a greater community awareness of healthy eating; (Danish report, machine translated) (Forskningscenter for Forebyggelse og Sundhed, 2016). SoL was a short 18 month project, with no significant impact on children's BMI reported. However, SoL showed that complex community projects can be an effective seed change in attitudes and behaviours, with scientists taking a facilitatory role only.

Place-based projects and groups can also allow communication in fragmented multi-level political structures. Taking an integrated role as investigator/activist, the lead researcher in an Exeter (UK) based project worked with citizens and other local actors to co-produce knowledge, despite a policy vacuum, to meet a rapidly evolving English urban food insecurity crisis (Sandover, 2020).

\section{Example 8 Food Literacy and Culture}

Beyond scientific benefits, citizen science also contributes to the knowledge, culture, and welfare of the citizens who contribute. For instance, an urban, Canadian healthy eating project (Growing roots), illustrates an effective approach to helping shift food cultures and practices. Immigrants to Winnipeg Manitoba tend to live in low-socioeconomic areas at risk of food insecurity and food poverty. Growing roots invited participants from immigrant communities to cooking classes, focusing on healthy Canadian meals and exploration of positive nutritional elements in participants indigenous food cultures. Although 
nutrition was not formally taught, participants reported learning and sharing peer-to-peer support through participatory and exploratory investigation of Canadian and group indigenous food practices (Henderson and Slater, 2019). This key study provides a template or framework to customise planetary diets, and healthy, sustainable food practices in different cultures, communities and geographies whilst respecting pre-existing practices and traditions.

\section{Conclusion and Recommendations for Future Research}

Traditional research and policy methods have proven insufficient for widespread change in diets, food practices and food production. Citizen science builds upon traditional research methods by providing a framework for investigation, while offering a concurrent platform for intervention, community engagement and teaching. Likewise, a food system transition requires participation of all actors (i.e. citizens involved in consumption, production, and change processes (example 4) based in sociocultural context (Spaargaren et al., 2012). Citizen science (and similar) methods are uniquely placed to contribute to this wider actor engagement and create real-world change.

The selected research examples discussed above demonstrate that citizen scientists have the potential to operate at many levels of the food system and at all levels of society. Participatory research can be facilitated by technology (examples 2-6) to help make distributed learning and dynamic sensing widespread, generating greater knowledge than may be possible with traditional research methods. Citizen science can also be used to evaluate awareness about food systems impact (Armstrong and Reynolds, 2020; Armstrong et al., 2020a,b). Shifts towards sustainable food systems and dietary patterns along with other positive health and food environment improvements can also be monitored and enabled through citizen science and wider participatory research methods (examples 2-6). However, further specific dietary change citizen science studies are needed, as this is a new field of investigation.

Participatory research in health (examples 6, 8) demonstrate that by looking within sociocultural systems and engaging the people within them, researchers and publics can gather diverse contextual perspectives and potentially generate more creative solutions to problems.

By fostering wide and diverse participation (Kimura and Kinchy, 2020), by working with citizens in an investigator activist sense (Stilgoe, 2009) researchers can help to broker engagement with a wider variety of actors. The examples described above indicate that citizen engagement and advocacy are more effective when policy makers engage (examples 6, 7). Citizen science has been (explicitly or implicitly) a tool for policymakers. However, to be a true force for change, the

\section{REFERENCES}

Akom, A., Shah, A., Nakai, A., and Cruz, T. (2016). Youth Participatory Action Research (YPAR) 2.0: how technological innovation and digital organizing evidence produced by food citizen science (and the research process itself) must impact policy and culture (Schröder et al., 2019).

As evidenced above, citizen science does not require necessarily the development of new research methods, but can easily fit within existing ones (adjusted to recognise that citizens have to collect data or engage with each other). For example, multiple participatory tools already exist that can be used to promote and embed citizen science approached within existing research programmes (see Pain et al., 2012, or Hall et al., 2017). Such tools should be used to facilitate citizen participation and ensure collaboration between professional science and society. This is essential to facilitate socio-technical sustainable transitions in the food system (Sauermann et al., 2020). We conclude that working together as citizen scientists, within and alongside place based structures, to seed networks and propagate change strategies, diverse citizen involvement can help embed new behaviours and cultural norms for a more sustainable food system.

\section{DATA AVAILABILITY STATEMENT}

The original contributions presented in the study are included in the article/supplementary material, further inquiries can be directed to the corresponding author.

\section{AUTHOR CONTRIBUTIONS}

CR: PI and grant holder, he peer-reviewed and assisted with writing the last version of this paper. LO: authored first draft. LP, XS, CF, GB, AK, and SS: peer-reviewed drafts. CW, CK, GM, and SS: initial project conception. All authors contributed to the article and approved the submitted version.

\section{FUNDING}

This work was funded by STFC Food Network+ pilot funding (ST/P003079/1), and STFC 21st Century challenge funding (ST/T001410/1) Piloting Zooniverse for food, health and sustainability citizen science. CR was supported from the HEFCE Catalyst-funded N8 AgriFood Resilience Programme and matched funding from the N8 group of Universities. Additional funding was provided by Research England via the project Food based citizen science in UK as a policy tool. Additional funding was provided by the Food Standards Agency to conduct an additional Rapid Evidence Assessment in December 2020. SS was supported in part by ESCAPE-The European Science Cluster of Astronomy \&Particle Physics ESFRI Research Infrastructures, which in turn received funding from the European Union's Horizon 2020 research and innovation programme under Grant Agreement No. 824064. sparked a food revolution in East Oakland. Int. J. Qual. Stud. Educ. 29, 1287-1307. doi: 10.1080/09518398.2016.1201609

Altieri, M. A., Companioni, N., Cañizares, K., Murphy, C., Rosset, P., Bourque, M. et al. (1999). The greening of the "barrios": Urban agriculture for food 
security in Cuba. Agric. Hum. Values 16, 131-140. doi: 10.1023/A:10075453 04561

Anand, S. S., Hawkes, C., De Souza, R. J., Mente, A., Dehghan, M., Nugent, R., et al. (2015). Food consumption and its impact on cardiovascular disease: importance of solutions focused on the globalized food system a report from the workshop convened by the World Heart Federation. J. Am. Coll. Cardiol. 66, 1590-1614. doi: 10.1016/j.jacc.2015.07.050

Armstrong, B., Bridge, G., Oakden, L., Reynolds, C., Wang, C., Panzone, L., et al. (2020a). Piloting citizen science methods to measure perceptions of carbon footprint and energy content of food. Front. Sustain. Food Syst. 4:120. doi: 10.3389/fsufs.2020.00120

Armstrong, B., Bridge, G., Oakden, L., Reynolds, C., Wang, C., Panzone, L., et al. (2020b). How does citizen science compare to online survey panels? a comparison of food knowledge and perceptions between the zooniverse, prolific and qualtrics UK panels. Front. Sustain. Food Syst. 4:575021. doi: $10.3389 /$ fsufs. 2020.575021

Armstrong, B., and Reynolds, C. (2020). China and the USA, a higher perceived risk for UK consumers in a post COVID-19 food system: the impact of country of origin and ethical information on consumer perceptions of food [version 1; peer review: 1 approved]. Emerald Open Res. 2:35. doi: 10.35241/emeraldopenres.13711.1

Beilin, R., and Hunter, A. (2011). Co-constructing the sustainable city: how indicators help us "grow" more than just food in community gardens. Local Environ. 16, 523-538. doi: 10.1080/13549839.2011.555393

Bénard-Capelle, J., Guillonneau, V., Nouvian, C., Fournier, N., Loët, K. Le, and Dettai, A. (2015). Fish mislabelling in France: substitution rates and retail types. PeerJ 2015, 1-21. doi: 10.7717/peerj.714

Bloch, P., Toft, U., Reinbach, H. C., Clausen, L. T., Mikkelsen, B. E., Poulsen, K., et al. (2014). Revitalizing the setting approach-supersettings for sustainable impact in community health promotion. Int. J. Behav. Nutr. Phys. Act. 11, 1-15. doi: 10.1186/s12966-014-0118-8

Buchmann, C. (2009). Cuban home gardens and their role in social-ecological resilience. Hum. Ecol. 37, 705-721. doi: 10.1007/s10745-009-9283-9

Buytaert, W., Zulkafli, Z., Grainger, S., Acosta, L., Alemie, T. C., Bastiaensen, J., et al. (2014). Citizen science in hydrology and water resources: opportunities for knowledge generation, ecosystem service management, and sustainable development. Front. Earth Sci. 2:26. doi: 10.3389/feart.2014.00026

Chrisinger, B. W., Ramos, A., Shaykis, F., Martinez, T., Banchoff, A. W., Winter, S. J., et al. (2018). Leveraging citizen science for healthier food environments: a pilot study to evaluate corner stores in Camden, New Jersey. Front. Public Health 6:89. doi: 10.3389/fpubh.2018.00089

Committee on Climate Change (2020). Land use: Policies for a Net Zero UK. 121. Available online at: https://www.theccc.org.uk/publication/land-use-policiesfor-a-net-zero-uk/ (accessed July 30, 2020).

Dehnen-Schmutz, K., Foster, G. L., Owen, L., and Persello, S. (2016). Exploring the role of smartphone technology for citizen science in agriculture. Agron. Sustain. Dev. 36, 1-9. doi: 10.1007/s13593-016-0359-9

Derr, V., and Simons, J. (2020). A review of photovoice applications in environment, sustainability, and conservation contexts: is the method maintaining its emancipatory intents? Environ. Educ. Res. 26, 359-380. doi: 10.1080/13504622.2019.1693511

Díez, J., Gullón, P., Vázquez, M. S., Álvarez, B., and Martín, M. del P., Urtasun, M., et al. (2018). A community-driven approach to generate urban policy recommendations for obesity prevention. Int. J. Environ. Res. Public Health 15, 1-15. doi: 10.3390/ijerph15040635

Disrupting Japan (2021). These Japanese Bio-Hackers Are Growing Affordable Meat in A Lab [Podcast]. Available online at: https://www.disruptingjapan. com/these-japanese-bio-hackers-are-growing-meat-in-a-lab-shojinmeat/ (accessed June 2, 2021).

Dobson, M. C., Reynolds, C., Warren, P. H., and Edmondson, J. L. (2020). "My little piece of the planet": the multiplicity of well-being benefits from allotment gardening. Br. Food J. doi: 10.1108/BFJ-07-2020-0593

Dobson, M. C., Warren, P. H., and Edmondson, J. L. (2021). Assessing the direct resource requirements of urban horticulture in the united kingdom: A citizen science approach. Sustainability 13:2628. doi: 10.3390/su130 52628

Dolejšová, M., and Kera, D. (2017). "Soylent diet self-experimentation: design challenges in extreme citizen science projects," in Proceedings of the ACM Conference on Computer Supported Cooperative Work, CSCW (Portland: ACM), 2112-2123. doi: 10.1145/2998181. 2998365

Edmondson, J. L., Childs, D. Z., Dobson, M. C., Gaston, K. J., Warren, P. H., and Leake, J. R. (2020). Feeding a city-Leicester as a case study of the importance of allotments for horticultural production in the UK. Sci. Total Environ. 705:135930. doi: 10.1016/j.scitotenv.2019.135930

Food and Agriculture Organization of the United Nations (FAO) (2018). Sustainable Food Systems. Concept and Framework. 1-8. Available online at: http://www.fao.org/3/ca2079en/CA2079EN.pdf (accessed November 3, 2020).

Forskningscenter for Forebyggelse og Sundhed (2016). Aalborg Universitet Steno Diabetes Center. Sundhed og Lokalsamfund-SoL. Available online at: https:// nordeafonden.dk/sites/nordeafonden.dk/files/media/rapport_-_projekt_ sundhed_og_lokalsamfund_-_sol.pdf (accessed April 20, 2020).

Fritz, S., See, L., Carlson, T., Haklay, M., Oliver, J. L., and Fraisl, D., et al. (2019). Citizen science and the United Nations sustainable development goals. Nat. Sustain. 2, 922-930. doi: 10.1038/s41893-019-0390-3

George, K. S., Roberts, C. B., Beasley, S., Fox, M., and Rashied-Henry, K. (2016). Our health is in our hands: a social marketing campaign to combat obesity and diabetes. Am. J. Heal. Promot. 30, 283-286. doi: 10.1177/0890117116639559

Haby, M. M., Chapman, E., Clark, R., Barreto, J., Reveiz, L., and Lavis, J. N. (2016). What are the best methodologies for rapid reviews of the research evidence for evidence-informed decision making in health policy and practice: a rapid review. Health Res. Policy Syst. 14:83. doi: 10.1186/s,12961-016-0155-7

Haklay, M. (2013). "Citizen science and volunteered geographic informationoverview and typology of participation," in Crowdsourcing Geographic Knowledge: Volunteered Geographic Information (VGI) in Theory and Practice, ed D. Z. Sui, S. Elwood, and M. F. Goodchild (Berlin: Springer), 1-396. doi: 10.1007/978-94-007-4587-2_7

Hall, R., Brent, Z., Franco, J., Isaacs, M., and Shegro, T. (2017). A Toolkit for Participatory Action Research, ed. K. Sandwell (TNI, FIAN, PLAAS, IISS). doi: 10.1186/s12961-016-0155-7

Harper, K., Sands, C., Angarita Horowitz, D., Totman, M., Maitín, M., Rosado, J. S., et al. (2017). Food justice youth development: using photovoice to study urban school food systems. Local Environ. 22, 791-808. doi: 10.1080/13549839.2016.1274721

Helenius, J., Hagolani-Albov, S. E., and Koppelmäki, K. (2020). Co-creating Agroecological Symbioses (AES) for sustainable food system networks. Front. Sustain. Food Syst. 4:588715. doi: 10.3389/fsufs.2020.588715

Henderson, A., and Slater, J. (2019). Growing roots: a newcomer nutrition program designed using action research methods. Ecol. Food Nutr. 58, 430-455. doi: 10.1080/03670244.2019.1636792

Hoolohan, C., McLachlan, C., and Larkin, A. (2019). 'Aha' moments in the water-energy-food nexus: a new morphological scenario method to accelerate sustainable transformation. Technol. Forecast. Soc. Change 148:119712. doi: 10.1016/j.techfore.2019.119712

Hoolohan, C., McLachlan, C., and Mander, S. (2018). Food related routines and energy policy: a focus group study examining potential for change in the United Kingdom. Energy Res. Soc. Sci. 39, 93-102. doi: $10.1016 /$ j.erss.2017.10.050

Ingram, J. (2011). A food systems approach to researching food security and its interactions with global environmental change. Food Secur. 3, 417-431. doi: 10.1007/s12571-011-0149-9

Israel, B. A., Schulz, A. J., Parker, E. A., and Becker, A. B. (1998). Review of community-based research: assessing partnership approaches to improve public health. Annu. Rev. Public Health 19, 173-202. doi: 10.1146/annurev.publhealth.19.1.173

Kallio, G., and Houtbeckers, E. (2020). Academic knowledge production: framework of practical activity in the context of transformative food studies. Front. Sustain. Food Syst. 4:57735. doi: 10.3389/fsufs.2020.577351

Kimura, A. H., and Kinchy, A. (2020). Citizen science in North American agri-food systems: lessons learned. Citiz. Sci. Theory Pract. 5:4. doi: 10.5334/cstp.246

Kopelman, P., Jebb, S. A., and Butland, B. (2007). "Tackling Obesities: Future Choices" Project Report. Foresight. 2nd Edn. London: Government Office for Science. Available online at: https://assets.publishing.service.gov.uk/ government/uploads/system/uploads/attachment_data/file/287937/07-1184xtackling-obesities-future-choices-report.pdf (accessed March 10, 2020). 
Kovacic, M. B., Stigler, S., Smith, A., Kidd, A., and Vaughn, L. M. (2014). Beginning a partnership with photovoice to explore environmental health and health inequities in minority communities. Int. J. Environ. Res. Public Health 11, 11132-11151. doi: 10.3390/ijerph111111132

Kuznetsov, S., Santana, C. J., and Long, E. (2016). "Everyday food science as a design space for community literacy and habitual sustainable practice," in Conference on Human Factors in Computing Systems-Proceedings (San Jose), 1786-1797. doi: 10.1145/2858036.2858363

Lang, T., and Mason, P. (2017a). Sustainable diet policy development: implications of multi-criteria and other approaches, 2008-2017. Proc. Nutr. Soc. 1-16. doi: $10.1017 /$ S0029665117004074

Lang, T., and Mason, P. (2017b). Sustainable Diets: How Ecological Nutrition Can Transform Consumption and the Food System, 1st Edn. Abingdon: Routledge.

Lanksbury, J. A., Carey, A. J., Niewolny, L. A., and West, J. E. (2013). Mussel Watch Pilot Expansion 2012/2013: a Study of Toxic Contaminants in Blue Mussels (Mytilus trossulus) From Puget Sound Washington, USA. Field Sample Summary and Progress Report. Puget Sound. Available online at: https://wdfw. wa.gov/sites/default/files/publications/01597/wdfw01597.pdf (accessed March $3,2020)$.

Mammen, S., Sano, Y., Braun, B., and Maring, E. F. (2019). Shaping core health messages: rural, low-income mothers speak through participatory action research. Health Commun. 34, 1141-1149. doi: 10.1080/10410236.2018.1465792

Martay, B., and Pearce-Higgins, J. W. (2018). Using data from schools to model variation in soil invertebrates across the UK: the importance of weather, climate, season and habitat. Pedobiologia (Jena) 67, 1-9. doi: 10.1016/j.pedobi.2018.01.002

Mbow, C. C., Rosenzweig, L. G., Barioni, T. G., Benton, M., Herrero, M., Krishnapillai, E., et al. (2019). Food Security. Clim. Chang. L. an IPCC Spec. Rep. Clim. Chang. Desertif. L. Degrad. Sustain. L. Manag. food Secur. Greenh. gas fluxes Terr. Ecosyst. Available online at: https://www.ipcc.ch/srccl/chapter/ chapter-5/ (accessed July 14, 2020).

Mosites, E., Lujan, E., Brook, M., Brubaker, M., Roehl, D., Tcheripanoff, M., et al. (2018). Environmental observation, social media, and One Health action: a description of the Local Environmental Observer (LEO) Network. One Heal. 6, 29-33. doi: 10.1016/j.onehlt.2018.10.002

Mylan, J. (2018). Sustainable consumption in everyday life: a qualitative study of UK consumer experiences of meat reduction. Sustainability 10:2307. doi: 10.3390/su10072307

Naydenova, S., de Luca, L., and Yamadjako, S. (2019). "Envisioning the expertise of the future," in EFSA Journal (Parma), 1-9. doi: 10.2903/j.efsa.2019.e 170721

Nielen, M. (2019). Citizen Science and Food Safety. Anal. Sci. Available at: https:// theanalyticalscientist.com/fields-applications/citizen-science-and-food-safety (accessed March 10, 2020).

Pain, R., Whitman, G., Milledge, D., and Lune Rivers Trust. (2012). Participatory action research toolkit: an introduction to using PAR as an approach to learning, research and action, Durham University/RELU/Lune Rivers Trust. Available online at: https://www.durham.ac.uk/media/durham-university/ research-/research-centres/social-justice-amp-community-action-centre-for/ documents/toolkits-guides-and-case-studies/Participatory-Action-ResearchToolkit.pdf (accessed July 6, 2020).

Pateman, R., de Bruin, A., Piirsalu, E., Reynolds, C., and West, S. (2020). Citizen science for quantifying and reducing food loss and food waste. Front. Sustain. Food Syst. 4:589089. doi: 10.3389/fsufs.2020.589089

Pérez-Belmont, P., Alvarado, J., Vázquez-Salvador, N., Rodríguez, E., Valiente, E., and Díaz, J. (2019). Water quality monitoring in the Xochimilco peri-urban wetland: experiences engaging in citizen science. Freshw. Sci. 38, 342-351. doi: 10.1086/703395

Poore, J., and Nemecek, T. (2018). Reducing food's environmental impacts through producers and consumers. Science 360, 987-992. doi: 10.1126/science. aaq0216

Popkin, B. M. (2017). Relationship between shifts in food system dynamics and acceleration of the global nutrition transition. Nutr. Rev. 75, 73-82. doi: 10.1093/nutrit/nuw064

Quesada-González, D., and Merkoçi, A. (2017). Mobile phone-based biosensing: an emerging "diagnostic and communication" technology. Biosens. Bioelectron. 92, 549-562. doi: 10.1016/j.bios.2016.10.062
Ramirez-Andreotta, M. D., Brusseau, M. L., Artiola, J., Maier, R. M., and Gandolfi, A. J. (2015). Building a co-created citizen science program with gardeners neighboring a superfund site: the gardenroots case study. Int. Public. Health J. 7:13.

Reese, A. T., Madden, A. A., Joossens, M., Lacaze, G., and Dunn, R. R. (2020). Influences of ingredients and bakers on the bacteria and fungi in sourdough starters and bread. mSphere 5, 1-15. doi: 10.1128/mSphere.00950-19

Reiher, C. (2016). Lay People and Experts in Citizen Science: Monitoring Radioactively Contaminated Food in Post-Fukushima Japan. Asien 140 S. 56-73.

Reynolds, C. (2020). "Sustainable Gastronomy: The Environmental Impacts of How We Cook Now and How Might the Sustainable-Diets Agenda Shape How We Cook in the Future?," in Food and Disruption 2020 (Dublin: Dublin Gastronomy Symposium), 202-209. doi: 10.21427/qgv5-tc04

Reynolds, C., Oakden, L., West, S., Pateman, R., and Elliott, C. (2021). Citizen Science and Food: A Review. London: Food Standards Agency. doi: $10.46756 /$ sci.fsa.nao903

Rogers, C., Johnson, J., Nueslein, B., Edmunds, D., and Valdez, R. S. (2018). "I love fruit but i can't afford it": using participatory action research to develop community-based initiatives to mitigate challenges to chronic disease management in an African American community living in public housing. J. Racial Ethn. Heal. Disparities 5, 1315-1327. doi: 10.1007/s40615-018-0480-3

Ross, G. M. S., Bremer, M. G. E. G., and Nielen, M. W. F. (2018). Consumer-friendly food allergen detection: moving towards smartphonebased immunoassays. Anal. Bioanal. Chem. 410, 5353-5371. doi: 10.1007/s00216-018-0989-7

Rosset, P. M., Sosa, B. M., Jaime, A. M. R., and Lozano, D. R. Á. (2011). The Campesino-to-campesino agroecology movement of ANAP in Cuba: social process methodology in the construction of sustainable peasant agriculture and food sovereignty. J. Peasant Stud. 38, 161-191. doi: $10.1080 / 03066150.2010 .538584$

Rosset, P. M., and Val, V. (2019). "The 'campesino a campesino' agroecology movement in Cuba," in Routledge Handbook Of Food As A Commons Expanding Approaches, eds J. L. Vivero-Pol, T. Ferrando, O. De Schutter, and U. Mattei (London: Routledge), 251-265. doi: 10.4324/9781315161495-16

Ryan, S. F., Adamson, N. L., Aktipis, A., Andersen, L. K., Austin, R., Barnes, L. et al. (2018). The role of citizen science in addressing grand challenges in food and agriculture research. Proc. R. Soc. B Biol. Sci. 285. doi: 10.1098/rspb.2018.1977

Sandover, R. (2020). Participatory food cities: scholar activism and the coproduction of food knowledge. Sustainability 12:3548. doi: 10.3390/su120 93548

Sauermann, H., Vohland, K., Antoniou, V., Balázs, B., Göbel, C., Karatzas, K., et al. (2020). Citizen science and sustainability transitions. Res. Policy 49:103978. doi: 10.1016/j.respol.2020.103978

Schröder, P., Vergragt, P., Brown, H. S., Dendler, L., Gorenflo, N., Matus, K. et al. (2019). Advancing sustainable consumption and production in cities-a transdisciplinary research and stakeholder engagement framework to address consumption-based emissions and impacts. J. Clean. Prod. 213, 114-125. doi: 10.1016/j.jclepro.2018.12.050

Shojinmeat Project (2021). Shojinmeat Project. Available online at: https:// shojinmeat.com/wordpress/en/ (accessed June 2, 2021).

Sijtsema, S. J., Fogliano, V., and Hageman, M. (2020). Tool to support citizen participation and multidisciplinarity in food innovation: circular food design. Front. Sustain. Food Syst. 4:582193. doi: 10.3389/fsufs.2020.582193

Sonnino, R., Tegoni, C. L. S., and De Cunto, A. (2019). The challenge of systemic food change: insights from cities. Cities 85, 110-116. doi: 10.1016/j.cities.2018.08.008

Spaargaren, G., Oosterveer, P., and Loeber, A. (2012). "Sustainability transitions in food consumption, retail and production," in Food Practices in Transition: Changing Food Consumption, Retail and Production in the Age of Reflexive Modernity (Abingdon, Routledge), 1-32.

Springmann, M., Clark, M., Mason-D'Croz, D., Wiebe, K., Bodirsky, B. L., Lassaletta, L., et al. (2018). Options for keeping the food system within environmental limits. Nature 562, 519-525. doi: 10.1038/s41586-018-0594-0

Steel, C. (2008). Hungry Cities: How Food Shapes Our Lives. London: Random House UK.

Steenhuis, I. H. M., and Vermeer, W. M. (2009). Portion size: review and framework for interventions. Int. J. Behav. Nutr. Phys. Act. 6, 58 doi: $10.1186 / 1479-5868-6-58$ 
Stilgoe, J. (2009). Citizen Scientists: Reconnecting Science With Civil Society. London. Available online at: https://www.demos.co.uk/files/Citizen Scientists_-_web.pdf (accessed July 6, 2020).

Strasser, B. J., Baudry, J., Mahr, D., Sanchez, G., and Tancoigne, E. (2018). "Citizen science"? rethinking science and public participation. Sci. Technol. Stud. 32, 52-76. doi: 10.23987/sts.60425

Sutton-Brown, C. A. (2014). Photovoice: a methodological guide. Photogr. Cult. 7 , 169-185. doi: 10.2752/175145214X13999922103165

Thow, A. M., and Hawkes, C. (2009). The implications of trade liberalization for diet and health: a case study from Central America. Global. Health 5, 1-15. doi: 10.1186/1744-8603-5-5

Tilman, D., and Clark, M. (2014). Global diets link environmental sustainability and human health. Nature 515, 518-522. doi: 10.1038/nature 13959

Toft, U., Bloch, P., Reinbach, H. C., Winkler, L. L., Buch-Andersen, T., AagaardHansen, J., et al. (2018). Project SoL-a community-based, multi-component health promotion intervention to improve eating habits and physical activity among Danish families with young children. Part 1: Intervention development and implementation. Int. J. Environ. Res. Public Health 15:1097. doi: 10.3390/ijerph15061097

Torjesen, I. (2019). WHO pulls support from initiative promoting global move to plant based foods. BMJ 365:11700. doi: 10.1136/bmj. 11700

Tricco, A. C., Antony, J., Zarin, W., Strifler, L., Ghassemi, M., Ivory, J., et al. (2015). A scoping review of rapid review methods. BMC Med. 13:224. doi: 10.1186/s12916-015-0465-6

Vermeulen, S. J., Campbell, B. M., and Ingram, J. S. I. (2012). Climate change and food systems. Annu. Rev. Environ. Resour. 37, 195-222. doi: 10.1146/annurev-environ-020411-130608

Warde, A. (2016). The Practice of Eating. Paperback. Malden: Polity Press.

Warner, K. A., Lowell, B., Timme, W., Shaftel, E., and Hanner, R. H. (2019). Seafood sleuthing: how citizen science contributed to the largest market study of seafood mislabeling in the U.S. and informed policy. Mar. Policy 99, 304-311. doi: 10.1016/j.marpol.2018.10.035

Wilbanks, R. (2017). Real vegan cheese and the artistic critique of biotechnology. Engag. Sci. Technol. Soc. 3, 1-25. doi: 10.17351/ ests2017.53

Willett, W., Rockström, J., Loken, B., Springmann, M., Lang, T., Vermeulen, S., et al. (2019). Food in the Anthropocene: the EAT-Lancet Commissionon healthy diets from sustainable food systems. Lancet 393, 447-492. doi: 10.1016/S0140-6736(18)31788-4

Würschum, T., Leiser, W. L., Jähne, F., Bachteler, K., Miersch, M., and Hahn, V. (2019). The soybean experiment ' 1000 Gardens': a case study of citizen science for research, education, and beyond. Theor. Appl. Genet. 132, 617-626. doi: 10.1007/s00122-018-3134-2

Yano, T., Phornwisetsirikun, S., Susumpow, P., Visrutaratna, S., Chanachai, K., Phetra, P., et al. (2018). A participatory system for preventing pandemics of animal origins: Pilot study of the Participatory One Health Disease Detection (PODD) system. JMIR Public Health Surveill. 4:e25. doi: 10.2196/publichealth.7375

Zilliox, S., Smith, J. M. (2018). Colorado's fracking debates: citizen science, conflict and collaboration. Sci Cult. (Lond) 27, 221-241. doi: 10.1080/09505431.2018.1425384

Conflict of Interest: CF was employed by RSK ADAS Ltd. GM is affiliated with Zooniverse which is a project at the University of Oxford. He advised on the development of this Perspective, he did not influence the analysis of the data or the results that were presented.

The remaining authors declare that the research was conducted in the absence of any commercial or financial relationships that could be construed as a potential conflict of interest.

Publisher's Note: All claims expressed in this article are solely those of the authors and do not necessarily represent those of their affiliated organizations, or those of the publisher, the editors and the reviewers. Any product that may be evaluated in this article, or claim that may be made by its manufacturer, is not guaranteed or endorsed by the publisher.

Copyright (C) 2021 Oakden, Bridge, Armstrong, Reynolds, Wang, Panzone, Rivera, Kause, Ffoulkes, Krawczyk, Miller and Serjeant. This is an open-access article distributed under the terms of the Creative Commons Attribution License (CC BY). The use, distribution or reproduction in other forums is permitted, provided the original author(s) and the copyright owner(s) are credited and that the original publication in this journal is cited, in accordance with accepted academic practice. No use, distribution or reproduction is permitted which does not comply with these terms. 